\section{Incapacidad del Estado para resolver los principales problemas del país}

El Salvador vive momentos turbulentos que demandan respuestas contundentes. La ola de violencia sigue presente en números alarmantes, con la novedad, en los últimos meses, de que va adquiriendo nuevas características que reflejan signos de mayor deshumanización y barbarie. La Policía Nacional Civil (PNC) reconoce que los homicidios presentan características especiales, como decapitaciones, cuerpos encontrados atados de pies y manos, metidos en bolsas negras o envueltos en sábanas, y, también muy preocupante, ejecuciones múltiples. En total, la PNC reporta 17 asesinatos múltiples desde enero hasta el 24 de junio del presente año. De ese total, 15 masacres han sido perpetradas en la zona rural y, siguiendo el patrón más común, la mayoría de víctimas han sido familias de escasos recursos. La otra nota que hace más cruel la ola de violencia en El Salvador es el ensañamiento con menores de edad. Según la Red para la Infancia y la Adolescencia (RIA) y la Red Nacional de Niñas, Niños y Adolescentes (RENAES), más de 100 homicidios de estudiantes entre 15 y 19 años se cometieron hasta el 30 de junio. Ese es el rango de edad de los jóvenes que cursan tercer ciclo y bachillerato. En el mismo período, los informes de la PNC reconocen solo 75 homicidios, la mayoría relacionada con el accionar de las pandillas.

No hay duda de que la violencia es un flagelo que castiga, con dureza y casi sin tregua, a la sociedad salvadoreña. Los grandes medios de comunicación, sobre todo los impresos, con gran empeño nos ponen cara a cara con estos hechos todos los días. Pero lo más decepcionante de esta situación es que no hay una explicación seria y profunda que identifique las causas últimas de esta violencia. Se le da cobertura al fenómeno y se llevan estadísticas pormenorizadas, pero se dice muy poco o nada sobre sus raíces. ¿Por qué el ensañamiento con adolescentes y jóvenes a quienes se les trunca abruptamente su futuro? ¿Por qué se dan las masacres de familias pobres -bebés y niños incluidos- de la zona rural? Las autoridades no pasan de vincular los asesinatos al accionar de las pandillas, a conflictos familiares y a suponer que responden a rencillas por la venta al menudeo de la droga; pero estas explicaciones no responden a una investigación profesional.

La preocupación generalizada por esta situación en El Salvador se refleja en el creciente número de observatorios sobre la violencia que llevan estadísticas de asesinatos y otros delitos, y que recogen algunas características de los mismos, pero no profundizan en el porqué de esta violencia aparentemente irracional. Los centros de pensamiento también se han quedado cortos en esta tarea, probablemente porque adentrarse en los dinamismos profundos que originan la violencia traerá, sin duda, consecuencias mayores

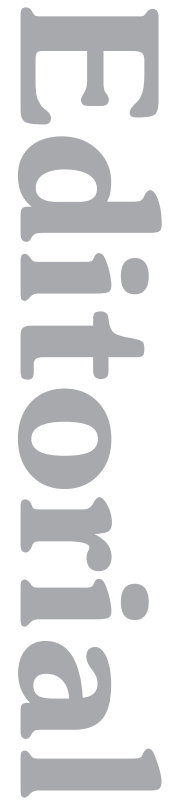


para quienes descubran qué y quiénes están detrás de este flagelo. Esta ausencia de interés, de voluntad o de capacidad para investigar las causas últimas de la violencia es lo más lamentable de esta situación, porque implica que se seguirán dando palos de ciego contra un fenómeno y no contra las raíces de donde se nutre.

\section{Remiendos en lugar de cambios estructurales}

Tampoco la crisis económica que ha golpeado a la familia salvadoreña parece dar signos de menguar en el futuro cercano. Consciente de que el problema más sentido por la población salvadoreña está referido a la difícil situación socioeconómica, el Gobierno del presidente Funes implementó una

A la fecha, después de que, a principios de año, el Gobierno anunciara a través del Secretario Técnico de la Presidencia, Alex Segovia, sus intenciones de llegar a un pacto fiscal con el sector empresarial antes de finalizar el año, no se ha dado ningún avance en el tema serie de medidas que pretenden aliviar el peso de la crisis. A inicios de abril, el Gobierno decretó un aumento salarial del $8 \%$ para los empleados del sector privado, redujo en $\$ 0.25$ el precio de las gasolinas, implementó un subsidio de tres meses al aumento de la tarifa de la energía eléctrica a los hogares que consumen hasta 300 kilovatios/hora, subió el subsidio del gas propano de $\$ 8.50$ a $\$ 9.10$, distribuyó frijol rojo importado a $\$ 0.75$ la libra y puso a disposición de los productores agrícolas cuarenta millones de dólares en créditos de hasta un techo de seis mil dólares al $4 \%$ de interés anual. Es decir, no se puede argumentar que el Gobierno no ha hecho nada al respecto, pero sí podemos preguntarnos si lo que ha hecho es lo más indicado o lo suficiente para hacer frente a la crisis. Por el momento, pareciera que la población no valora que estas medidas hayan aliviado su situación y esperan mucho más de la presente gestión. El anuncio del Gobierno, hecho en el mes de mayo, de un impuesto para financiar la seguridad y que afectaría a las personas naturales o jurídicas cuyo patrimonio fuese igual o superior a los $\$ 500000$ no ha pasado de ser un anuncio ante la visceral oposición de los más ricos del país.

Las medidas de apoyo a la población para aliviar la crisis económica suponen un incremento en el ya abultado déficit fiscal. A pesar de las recomendaciones de varios organismos internacionales, acerca de la necesidad de focalizar este tipo de subsidios hacia los que verdaderamente lo necesitan y de incrementar la carga fiscal, para que el país pueda hacer frente a las necesidades de gasto e inversión social, el Gobierno no se ha atrevido a iniciar la reforma fiscal que le permitiría disponer de los recursos que necesita. A la fecha, después de que, a principios de año, el Gobierno anunciara a través del Secretario Técnico de la Presidencia, Alex Segovia, sus intenciones de llegar a un pacto fiscal con el sector empresarial antes de finalizar el año, no se ha dado ningún avance en el tema.

Tampoco han avanzado, más allá de su discusión en el seno del Consejo Económico y Social, dos de las principales apuestas del Gobierno del presidente Funes para impulsar la economía nacional. Ni la ley de creación del sistema financiero nacional para el desarrollo ni la ley que dé carta de ciuda- 
danía a los asocios público-privados han sido discutidas o aprobadas en la Asamblea Legislativa.

\section{Agarrados a las propuestas que vienen del Norte}

En la víspera de cumplir su segundo año de gestión, el Gobierno anunció a bombo y platillo el "asocio para el crecimiento" (Partnership to Grow) durante la visita del presidente Barack Obama al país el pasado mes de marzo. El Salvador -junto a Ghana, Filipinas y Tanzania- es uno de los cuatro países seleccionados por la nación del norte como destinatarios de esta medida. Según rezan los objetivos del plan, se persigue combatir los principales obstáculos al crecimiento económico, pues, como es conocido, El Salvador se mantiene a la zaga de este rubro en América Latina. El programa se ejecutará a partir del segundo semestre de este año y terminará su implementación en el año 2016. Este asocio se incluirá en el cuestionado plan quinquenal del Gobierno, cuyas metas y prioridades se están revisando para relanzarlo. Según el secretario técnico de la Presidencia, ahora ya se tienen claros los montos de lo que el país captará en concepto de ingresos desde el exterior, y los nacionales hasta el año 2014; por tanto, afirma, se puede hacer un ejercicio más realista.

\section{En los períodos en los que el país ha registrado mayor crecimiento económico, este no se ha traducido en una disminución de la desigualdad, sino en todo lo contrario} sacar al país del atolladero en que está desde hace algún tiempo. Aunque debemos esperar el desarrollo de la iniciativa y, sobre todo, los frutos de la misma, debe advertirse que el crecimiento no equivale por fuerza a desarrollo y que el desarrollo no se traduce automáticamente en equidad. Hasta donde se conoce, el "asocio para el crecimiento" se enfoca en la eliminación de las restricciones que impiden el crecimiento económico, pero no se especifican medidas que garanticen que los réditos que produzca el crecimiento no se queden en pocas manos, como ha sucedido siempre. La historia es madre y maestra, dice la sentencia, y deberíamos aprender que, en los períodos en los que el país ha registrado mayor crecimiento económico, este no se ha traducido en una disminución de la desigualdad, sino en todo lo contrario. Emblemática parece ser la década de los años setenta en la que se registraron altos niveles de crecimiento ("el Japón de Centroamérica", llamaban, entonces, a El Salvador) que contrastaron con la situación socioeconómica de la mayoría de la población, lo cual tuvo como derrotero la fratricida guerra civil cuyas secuelas todavía estamos padeciendo. Se espera que la metodología y el proceso en los que trabajarán diez expertos estadounidenses más otros tantos nacionales arrojen resultados que posibiliten el crecimiento indispensable para el desarrollo, pero es urgente que se definan, simultáneamente, medidas que garanticen que el crecimiento llegue a toda la población, so pena de ensanchar todavía más la brecha entre ricos y pobres que nos ubica en la región más desigual del mundo. 
La difícil situación económica y de violencia obliga a preguntarse por la capacidad del Estado para enfrentarlas. Es decir, además del desempeño del Gobierno, deberíamos ser conscientes de que la institucionalidad del país está todavía en proceso de construcción. Las instituciones del Estado salvadoreño siguen respondiendo más a la defensa de intereses particulares que a la función que les asignan las leyes del país. El 5 de abril, la Fiscalía General de la República (FGR) ejecutó, con gran cobertura mediática, la captura del ministro de Salud (del Gobierno de Antonio Saca), Guillermo Maza, y doce personas más, acusadas por los delitos de estafa agravada, falsedad documental y negociaciones ilícitas. Tres días después, solamente dos personas quedaron detenidas, dejando libres a las otras once por falta de pruebas contundentes. Esta acción de la FGR puede leerse como un intento de la Fiscalía de reivindicarse ante los constantes cuestionamientos que recibe por su falta de eficacia. La captura de los supuestos corruptos tuvo lugar pocos días después de que el presidente Funes anunciara su deseo de constituir una Comisión Internacional -al estilo de la CICIG de Guatemala- para investigar al crimen organizado y después de que la Embajada de los Estados Unidos reclamara por el retraso en la instalación del centro de escuchas telefónicas. La FGR es un claro ejemplo de que la institucionalidad del Estado es muy débil y no está en condiciones de enfrentar los graves problemas del país.

\section{La crisis institucional generada por el decreto 743}

A principios de junio, la inesperada y veloz aprobación del decreto 743 puso en evidencia la fragilidad de la institucionalidad del país. Algunos analistas coincidieron en señalarla como la crisis más grave que ha atravesado El Salvador desde la firma de los Acuerdos de Paz, en el año 1992. La crisis se desató cuando dicho decreto fue aprobado por los partidos de derecha y fue sancionado por el presidente Funes con una celeridad desconocida hasta entonces, con la complicidad solapada del FMLN y con dedicatoria especial para la Sala de lo Constitucional de la Corte Suprema de Justicia. Las raíces de esta crisis hay que buscarlas en el pasado.

Durante el conflicto armado, los dos actores protagónicos estaban bien definidos y todos los actores de reparto -nacionales e internacionales- se situaban alrededor de las dos fuerzas beligerantes del país. Después de la firma de la paz, hace casi veinte años, fueron los partidos políticos los que, gradualmente, asumieron el rol principal. Los poderes fácticos han tenido que defender sus intereses y buscar sus objetivos a través del sistema de partidos. Se esté de acuerdo o no con la dinámica electoral del país, la vena aorta del sistema político salvadoreño son las elecciones. Durante casi dos décadas, los partidos políticos se han repartido el poder según las cuotas que les dan los resultados electorales, especialmente en la Asamblea Legislativa. Las principales decisiones de país no se han tomado persiguiendo el interés general de la población, sino los intereses particulares de los sectores representados en los partidos políticos. Para lograr sus pretensiones, los partidos tradicionales han violentado sistemáticamente la legislación nacional primaria y secundaria sin mayor ruido que el de las protestas de algunos sectores, incluyendo el otrora opositor FMLN. 
Esta dinámica perversa de manejar los asuntos de interés nacional respondiendo a intereses particulares a través de los partidos es lo que, en realidad, ha obstaculizado enfrentar los principales problemas de la población con soluciones acertadas. Gran parte de la sociedad salvadoreña hizo explícito su deseo de un cambio en las elecciones de marzo del 2009; sin embargo, los signos esperanzadores de un nuevo modo de hacer la política se originaron en un actor inesperado: la Sala de lo Constitucional de la Corte Suprema de Justicia. Separándose de la acostumbrada mala imagen del máximo tribunal judicial del país, al que solo un $9.5 \%$ de la población le otorga alguna confianza -según el Instituto de Opinión Pública de la UCA (IUDOP) en la evaluación del 2010-, cuatro de los cinco magistrados que componen la Sala comenzaron a propiciar los más radicales cambios que pueden posibilitar un avance en el fortalecimiento de la institucionalidad, del Estado de Derecho, y en la democracia del país. Los dos pilares sobre los que debe asentarse el trabajo del sistema judicial -la imparcialidad y la independencia- han sido suficientemente demostrados por la actual Sala de lo Constitucional. Su actividad, apegada al mandato constitucional y legal recibido, ha hecho que sus sentencias cuestionen prácticas de instancias del Estado que, aunque reñidas con la ley y la democracia, han sido el pan diario de sus actuaciones. Sus sentencias han declarado inconstitucionales prácticas de la Presidencia de la República, de la prensa nacional, de la Fiscalía General de la República, de la misma Corte Suprema de Justicia y de los partidos políticos. Es decir, la actuación de los cuatro magistrados de la Sala de lo Constitucional tocó a los poderes del país y cuestionó lo que antes denominamos la "vena aorta" del sistema político salvadoreño. Sus sentencias mandaron a legislar para que la población elija directamente a sus representes en la Asamblea

La situación económica requiere medidas que vayan más allá de las simplemente compensatorias y populistas Legislativa a través de la fotografía, para eliminar las listas cerradas, y ordenaron la cancelación de los partidos de Conciliación Nacional y Demócrata Cristiano, que debieron haber desaparecido al no alcanzar el mínimo exigido por la ley en las elecciones del 2004. Estas sentencias suponen un cambio radical al quitarles, a las cúpulas partidarias, la potestad de repartirse los lugares de toma de decisión.

Por esta irreverencia contra la forma de hacer política en el país, era urgente, para los afectados, quitar de en medio a los cuatro magistrados. Un acontecimiento externo fue decisivo para resolver hacerlos a un lado. El 30 de abril, el juez español Eloy Velasco, de la Audiencia Nacional de España, decretó auto de procesamiento contra veinte militares retirados salvadoreños por considerarlos sospechosos de la autoría intelectual de la masacre de la UCA en la que murieron dos mujeres laicas y seis sacerdotes jesuitas. Los militares ocupaban puestos claves de la institución castrense cuando se perpetró la masacre. Y el proceso en España apuntaba a que se emitiría una difusión roja por parte de la INTERPOL para su captura con miras a extraditarlos. Esto también es inaceptable para quienes han hecho lo que han querido con el país, por lo que anticipándose a los acontecimientos, se decidió silenciar desde antes a los cuatro magistrados. 
La manera que encontraron fue aprobar el decreto 743, que exige la unanimidad de los cinco magistrados en las sentencias de inconstitucionalidad, una unanimidad que es imposible en la práctica porque siempre han tenido la oposición del quinto magistrado, y que, además, constituye una aberración jurídica para este tipo de tribunales. El tristemente famoso decreto 743 fue aprobado por 47 votos de los partidos de derecha (ARENA, GANA, PCN y PDC), violando el procedimiento correcto. Pero lo que más sorprendió a propios y extraños es que el freno al cambio político más importante desde los Acuerdos de Paz fue dado por el presidente Funes al sancionar un decreto que, a todas luces, cercena el control constitucional y cuyo ejercicio mantuvo la esperanza de que el cambio era posible.

Esta coyuntura produjo la indignación en buena parte de la sociedad que ha visto con simpatía la valentía de los cuatro magistrados. Y si bien esta indignación no se tradujo en un movimiento de protesta masivo, sí produjo la inédita conjunción de un variopinto paisaje de la sociedad civil organizada, la cual aglutinó desde instancias identificadas tradicionalmente como de izquierda hasta la representación de la empresa privada, todas juntas exigiendo la derogación del decreto 743.

Sea por estrategia política o por responsabilidad con la justicia, el partido ARENA, en una jugada astuta, reconoció públicamente su yerro y pidió al FMLN acompañarlo en la solicitud de derogatoria del mencionado decreto. El FMLN, que hasta entonces había criticado la actuación de los partidos de derecha, cayó con sobresaliente ingenuidad política en la trampa de ARENA. Tiene en sus votos hacer realidad la derogatoria, pero se ha negado hasta el momento con argumentos que revelan que estaba de acuerdo con el decreto y que sus móviles son tan mezquinos como los de los partidos de derecha. Y es que, desde que llegó al poder en el 2009, el FMLN ha adoptado como propias las reglas del juego de los partidos tradicionales y ha reproducido, ya en el poder, lo que por veinte años criticó con tanta vehemencia.

El resultado momentáneo de esta crisis ha sido que una sucia maniobra de los partidos de derecha está dejando como perdedores al partido de izquierda y al presidente que llevó al poder. Decimos "perdedores" en cuanto a costos políticos se refiere, porque en realidad, en este escenario, el gran perdedor es, como siempre, el pueblo salvadoreño y su incipiente democracia.

Por todo lo dicho arriba, se puede afirmar que El Salvador vive momentos turbulentos que demandan respuestas contundentes. La situación económica requiere medidas que vayan más allá de las simplemente compensatorias y populistas. La crisis de inseguridad ha llegado a límites insospechados $\mathrm{y}$, al no conocer las raíces del fenómeno, nada garantiza que las medidas implementadas produzcan los frutos esperados por todos. Y como telón de fondo, la institucionalidad del país sufre una fuerte crisis cuando se tenía la esperanza de que las cosas podían comenzar a cambiar. Todo ello puede ser la oportunidad para iniciar un verdadero cambio en lugar de intentar maquillar un sistema y un modelo que parecen agotados. 